\title{
You Have What? Personality! Traits That Predict Leadership Styles for Elementary Principals
}

\author{
Melinda Garcia, Phyllis Duncan, Meghan Carmody-Bubb, Malcom James Ree \\ School of Business and Leadership, Our Lady of the Lake University, San Antonio, USA \\ Email: iigsawmg@hotmail.com
}

Received 27 December 2013; revised 25 January 2014; accepted 23 February 2014

Copyright $@ 2014$ by authors and Scientific Research Publishing Inc.

This work is licensed under the Creative Commons Attribution International License (CC BY). http://creativecommons.org/licenses/by/4.0/

(c) (i) Open Access

\section{Abstract}

This study of 242 teachers and paraprofessionals explored relationships between the followers' perceptions of the elementary principal's Big Five Personality Traits and the followers' perceptions of the elementary principal's Full Range Leadership Model for one school district in South Texas that included 8 elementary schools that participated in the research. The Multifactor Leadership Questionnaire 5X Short (MLQ) (Bass \& Avolio, 2004), The International Personality Item Pool (IPIP) (Goldberg, 1999), and a demographic survey created by the researcher, was used to collect data. This sample of convenience used a multiple regression to find correlations. Partial correlations and $t$-tests were used for further analyses. This particular study was based on followers' perceptions and did not support previous research that Extraversion is a predictor of leadership style. The study found relationships between perceived personality traits and leadership styles for four out of the five personality traits. Open, Agreeable, and Emotionally Stable principals were perceived to be Transformational Leaders. Open and Emotionally Stable principals were also perceived as Transactional Leaders. When principals were rated as Conscientious and Emotionally Unstable, they were perceived as Passive-Avoidant Leaders. The personality and leadership style that the principal's project does impact the followers' perceptions. Most studies in the literature review include self-ratings of personality and leadership while the present study used followers' ratings of the leader's personality and leadership. Perception is reality. Surprisingly, the followers' ratings for principals' leadership styles and Extraversion were non-significant.

\section{Keywords}

Follower Perceptions; Personality; Leadership; Extraversion; The Big Five Personality Traits; Transformation Leadership; Transactional Leadership; Passive Avoidant Leadership 


\section{Introduction}

\section{Leadership}

Leadership impacts the lives of many individuals and none more so than educational leadership. According to Moffet (1979), leadership is vital to education because leadership sets the foundation for learning. According to Bennis (1989), “To an extent, leadership is like beauty: It is hard to define, but you know it when you see it” (p. 1). Leadership is like a tornado: leadership encapsulates everything in its path and leaves a lasting effect. As a result, change is imminent for those leaders who are truly effective. "Leadership is such a gripping subject that once it is given center stage, it draws attention away from everything else" (Gardner, 1990, xvi). Regardless of the many directions that a leader is pulled, keeping a clear vision for the organization is essential because the leader must lead with integrity, value, and trust with a purpose (George, 2003). Leadership is vital to education because leadership creates the foundation for the commitment to learning, especially in the elementary grade level. The role of the elementary school principal has undergone major changes that require the principal to have a refocused approach to maintaining the vision (Ferrandino, 2001).

Moffett, a principal, suggests that elementary schools are viewed as important institutions because elementary education is "the beginning of formal education for students" (Moffett, 1979, ๆ 5). The role of the principal in elementary schools is becoming more challenging. Principals are tasked with providing an environment that not only embraces creativity for learning, but also generates change elements that will create high performing schools (Moore, 2009).

The impact of leadership in an educational setting is conducive to much scrutiny because schools are rated by results from state mandated tests and attendance, among other parameters. According to Davis, Darling-Hammond, LaPointe, and Meyerson (2005), principals play a crucial role in the guidance of successful schools; as a result, the principals are constantly being scrutinized to improve learning and teaching. Due to the demands placed on the principals, who are often seen as visionaries and leaders, the job of a principal can seem quite daunting. At this heightened level of school leadership, principals have a great impact on followers: teachers, paraprofessionals, students, and parents (Davis et al., 2005). Pressure is placed on principals to provide more learning opportunities in order to lead their school effectively, which has to do with the strengths of the principal (Lewis, Cruzeiro, \& Hall, 2007).

According to Connelly (2008), the principal's role has become more complex, requiring principals to demonstrate courage, vision, and the skill to advocate in order for effective learning to take place for both students and adults. The principal is expected to be more of a transformational leader because the principal shares a vision, sustains it, and encourages others in a demanding, constantly changing society (Connelly, 2008).

Personal characteristics of a leader, such as abilities and personality, are direct antecedents of leader behavior, according to the multidimensional model of leadership (Chelladurai, 1980, 1993). It is one thing to rate one's self and how one perceives one's self to be a leader, but rating leadership is entirely different when rated by followers. Schyns and Sanders (2007) suggested it is imperative to determine the extent of the followers' perceptions in order to gauge the real behavior of the leader. Felfe and Schyn's (2010) study focused on the effect of followers' evaluation of leadership based on perceptions and attributions. In this particular study, the influence of the follower's personality on the follower's perceptions of leadership within an organizational setting was analyzed. The results concluded that the follower's personality does influence the perception of the leader's transformational leadership and the follower's commitment to the supervisor. This is just one example of how leaders are viewed by the followers.

Followers' perceptions of the leader should provide valuable feedback because leaders do impact followers'. According to Lord and Maher (1991), being perceived as a leader affects social and self-evaluations as well as the ability to create or limit job opportunities. It also increases the ability of the leaders to utilize resources needed by their organizations.

Over the years, much research has been conducted on leadership and personality to see if correlations exist. Kenny and Zaccaro (1983) noted that previous studies have failed to identify traits that are correlated to leadership because few of the same traits were being investigated across the studies. Using the Five-Factor Model of personality to organize the myriad of traits sheds considerable light on the dispositional basis of leadership (Judge, Bono, Llies, \& Gerhardt, 2002). Research does indicate that personality traits are related to leadership. In Judge, Bono, Llies, and Gerhardt's (2002) meta-analysis of 222 correlations from 73 samples of the traits perspective in leadership, results suggested that extroversion was indeed related to the emergence of the leader rather than the effectiveness of the leader. Sociable and dominant individuals are more likely to assert them- 
selves within group settings because they are extroverted, which is a part of the Big Five personality traits.

\section{Statement of the Problem}

Linking leadership and personality is critical in helping to identify a leader's effectiveness in administrative roles at the elementary level. The ideal administrator will encompass certain characteristics that will enable the individual to make decisions so followers will be able to attain success. Previous studies state that definite traits can be linked between personality and leadership, but the studies lacked a structure for personality (Judge et al., 2002). Prior studies between personality and leadership recognized leadership only in two categories: emergence and effectiveness (Judge et al., 2002).

\section{Purpose of the Study}

Research by Judge and Bono (2000), Judge et al. (2002), Karaköse (2008), and Chelladurai (1980, 1993), to name a few, has provided a plethora of information on leadership and how personality can affect the type of leader that an individual is or can become. Strides have been taken to address correlations between personality and leadership in individual studies as well as meta-analyses. However, most studies used self-ratings of the leader, rather than ratings of the leader's personality from the followers' perspective. The article by Sosik, Avolio, and Jung (2002), argue that self-presentation may play an important role in creating perceptions of leadership. The present study focused on elementary principals at a school district in South Texas using follower's ratings of the Big Five Personality Traits and The Full Range Leadership Model. Specifically, the present study examined whether there is a relationship between followers' perceptions of the principals' Big Five Personality Types (Openness, Conscientiousness, Extraversion, Agreeableness, and Neuroticism) and followers' perceptions of the principals' Full Range Leadership Model: Transformational, Transactional, and Passive Avoidant Leadership (Bass \& Avolio, 2004), when controlling for age, education, ethnicity, gender, professional development, and tenure. For the purpose of this study, followers were defined as elementary teachers and paraprofessionals.

\section{Leadership and Elementary Administrators}

Karaköse (2008) conducted a study to investigate perceptions of primary (elementary) schoolteachers on principal culture leadership behaviors. A one-way Analysis of Variance (ANOVA) was used to look at differences in cultural leadership based on experience. This study randomly selected 308 teachers and evaluated the teachers' perceptions of the principal using the Cultural Leadership Scale (Karaköse, 2008). There were significant differences found for the principal's cultural leadership ratings (affirmative) as a function of experience. The Tukey HSD results indicated that teachers who taught from $1-10$ years were significantly more affirmative than those teachers who had over 21 years of experience (Karaköse, 2008).

\section{Followers Perceptions of Personality and Leadership}

Lord De Vader, and Alliger (1986) conducted a meta-analysis of 27 studies analyzing relationships between personality traits and leadership perceptions. Results supported expectations with respect to gender (masculinity/femininity), intelligence, and dominance as related to leadership perceptions. The study found that personality traits were associated with leadership perceptions. Introversion/Extroversion were not good estimates of population values when contingency theories relating to perceptions of leadership effectiveness were present.

Moss and Ngu (2006) examined relationships between personality and influence towards leadership styles among 166 nursing employees in which only seven were male. The sample was taken from two public hospitals in Australia. The Neo-Five Factor Inventory (NEO-FFI; Costa \& McCrae, 1992) was used to measure the Big Five Personality Traits and the Multi-Factor Leadership Questionnaire Form 5X Short (MLQ; Avolio \& Bass, 2002) was used to measure leadership styles. Results from a regression analysis indicated that Extraversion and Conscientiousness were positively related to Transformational Leadership. On the other hand, Agreeableness and Openness were inversely related towards Transactional Leadership. Neuroticism was positively associated towards Laissez-Faire Leadership.

Anderson and Vecchio (2009) examined agreements between leader effectiveness and various demographic attributes. For the study, 1221 managers were examined via a $360^{\circ}$ feedback as correlates of leadership effectiveness. Self, superiors, peers, and subordinates used the Leadership Circle Profile instrument to measure beha- 
vioral differences. A self-assessment was also used to measure leader effectiveness on a five-item Likert-scale. The participants were mostly comprised of males (61.7\%) who were predominantly white (84.1\%) and educated (87.7\%). Ratings were also gathered from subordinates and peers. Results found relationships between the personality dimension of social dominance (Extraversion) for leader effectiveness and the feedback from peers.

\section{Method}

\section{Participants and Design}

The 242 participants for the sample of convenience study consisted of both teachers and paraprofessionals from eight elementary schools from a school district in South Texas. The mean age was 42.39 with a standard deviation of 10.6. Their educational levels consisted of high school (3.3\%), some college (9.9\%), bachelor's degree (50.8\%), and a master's degree (35.5\%). The ethnicity of the participants is as follows: Hispanic $81.4 \%$, White 18\%, African American .8\%, and Asian .4\%. For analysis purposes for ethnicity, Whites, African Americans, and Asians were collapsed into "Other" category, the majority of which were White. The genders of the participants' were $89.7 \%$ female and $10.3 \%$ male.

\section{Variables}

\subsection{Dependent Variables}

The dependent variables were the components of The Full Range Leadership Model: Transformational Leadership Style, Transactional Leadership Style, and Passive Avoidant Leadership Style. Transformational Leadership Style consists of Inspirational Motivation, Idealized Influence, Intellectual Stimulation, and Individualized Consideration. Transactional Leadership Style consists of Contingent Reward and Management-by-ExceptionActive. The last component of The Full Range Leadership Model is Passive Avoidant Leadership Style, which consists of Management-by-Exception-Passive and Laissez-Faire. See Figure 1 for a visual representation of The Full Range Leadership Model.

- Full Range Leadership Model—a model of leadership based on over 100 years of research that includes Transformational Leadership, Transactional Leadership, and Passive Avoidant Leadership (Barbuto \& Cummins-Brown, 2007).

- Transformational Leadership-involves a leader-follower exchange relationship in which the followers feel trust, loyalty, and respect toward the leader, and are motivated to do more than originally expected (Bass, 1985).

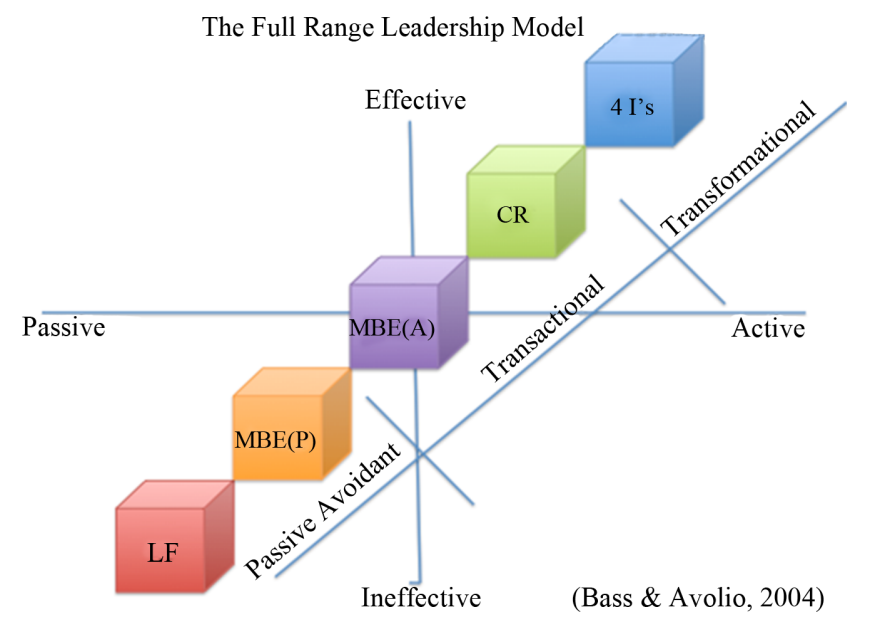

Figure 1. The Full Range Leadership Model, Note: The progression of the Full Range Leadership Model starts off at the top with Transformational Leadership being the most effective type of leadership then slowly progressing down to Transactional Leadership, middle of the road leadership, and lastly, Passive Avoidant Leadership, or lack of leadership. 
- Transactional Leadership—involves a leader-follower exchange relationship in which the follower receives some reward related to lower-order needs in return for compliance with the leader's expectations (Bass, 1985).

- Passive Avoidant Leadership-part of the Full Range Leadership Model that includes ManagementBy-Exception-Passive and Laissez-Faire in which no action is taken by the leader until it is too late (Daft, 2008).

\subsection{Independent Variables}

The independent variables consisted of the Big Five Personality Traits (Openness, Conscientiousness, Extraversion, Agreeableness, and Neuroticism).

- Big Five Personality Traits-five general dimensions that describe personality, Openness, Conscientiousness, Extraversion, Agreeableness, and Neuroticism (Daft, 2008).

- Openness - the degree to which a person has a broad range of interests and is imaginative, creative, and willing to consider new ideas (Daft, 2008).

- Conscientiousness - the degree to which a person is responsible, dependable, persistent, and achievementoriented (Daft, 2008).

- Extraversion - the degree to which a person is outgoing, sociable, talkative, and comfortable meeting and talking to new people, a Big Five Personality Trait (Daft, 2008).

- Agreeableness - the degree to which a person is able to get along with others by being good-natured, cooperative, forgiving, compassionate, understanding, and trusting (Daft, 2008).

- Neuroticism (emotional stability) - the degree to which a person is well adjusted, calm, and secure (Daft, 2008).

\subsection{Independent Control Variables}

The independent control variables consisted of the variables from the followers' demographics: age, education, ethnicity, gender, professional development, and tenure.

\section{Materials and Procedure}

The current study was conducted to determine if relationships existed between specific personality traits and specific leadership styles for elementary principals as perceived by followers when controlling for followers' age, education, ethnicity, gender, professional development, and tenure. The participants' demographic information was used as control variables. Two instruments were distributed to teachers and paraprofessional to rate their elementary principals: the International Personality Item Pool (IPIP; Goldberg, 1999) for personality, and the Multifactor Leadership Questionnaire Rater Form (5X-short) (MLQ; Bass \& Avolio, 2004) for leadership styles. The instruments were given to participants choosing to voluntarily complete the surveys once they had read an informed consent form for the study. Surveys were collected the day of distribution at each school.

The collection of data consisted of three sections: the demographic survey (follower information); International Personality Item Pool (IPIP) (Goldberg, 1999) used to measure the Big Five personality types, and the Multifactor Leadership Questionnaire 5X-Short (MLQ) (Bass \& Avolio, 2004) in which the follower's rated the principal's leadership behavior.

The demographic survey was the information gathered from the followers. The survey included the followers' age, education, ethnicity, gender, professional development, and tenure.

The IPIP is a 50 question standard questionnaire used to measure the Big Five Personality Traits on a scale from 1 to 5 (1-Very Inaccurate, 2-Moderately Inaccurate, 3-Neither Inaccurate nor Accurate, 4-Moderately Accurate, and 5-Very Accurate). The reliability ranges from .82 to .93 . Validity was established via factor analysis.

The MLQ is a 45-question survey; one of the most respected and efficient instruments used to measure leadership styles of The Full Range Leadership Model. It uses a Likert scale and measures from 0 to 4 (0 - Not At All, 1-Once In a While, 2-Sometimes, 3-Fairly Often, and 4-Frequently, If Not Always). The reliability ranges from .74 to .94 . 


\section{Study Hypotheses}

H1: There is a relationship between the followers' perceptions of the principal's Big Five Personality Types (Openness, Conscientiousness, Extraversion, Agreeableness, and Neuroticism) and followers' perceptions of the principal's Transformational Leadership Style (Inspirational Motivation, Idealized Influence, Intellectual Stimulation, and Individualized Consideration) when controlling for the followers' age, education, ethnicity, gender, professional development, and tenure?

H2: There is a relationship between the followers' perceptions of the principal's Big Five Personality Types (Openness, Conscientiousness, Extraversion, Agreeableness, and Neuroticism) and followers' perceptions of the principal's Transactional Leadership Style (Contingent Reward and Management-By-Exception-Active) when controlling for the followers’ age, education, ethnicity, gender, professional development, and tenure?

H3: There is a relationship between the followers' perceptions of the principal's Big Five Personality Types (Openness, Conscientiousness, Extraversion, Agreeableness, and Neuroticism) and followers' perceptions of the principal's Passive Avoidant Leadership Style (Management-By-Exception-Passive and Laissez-Faire) when controlling for the followers’ age, education, ethnicity, gender, professional development, and tenure?

\section{Results}

Multiple regression analyses were conducted on each of the null hypotheses in which the significance level was at $p<.05$. For categorical variables that were significant, $t$-tests were conducted to interpret differences between the means.

\section{Summary of Findings for The Full Range Leadership Model}

The following table (Table 1) lists descriptive statistics for the number of participants, mean, median, and mode of The Full Range Leadership Model, which are the dependent variables. Table 2 provides the summary of The Full Range Leadership Model findings.

The most frequent predictor for the entire Full Range Leadership Model was Neuroticism. The more Emotionally Stable and more active the teachers/paraprofessionals perceived the principals, the more Transformational and Transactional they rated the principal. The more Emotionally Unstable the teachers/paraprofessionals perceived the principals, the more Passive-Avoidant they rated the principal. Openness was the second most frequent predictor of both Transformational and Transactional Leadership. The more imaginative, had excellent ideas the teachers/paraprofessionals perceived the principals, the more Transformational and Transactional they rated the principal.

\section{Discussion of Findings}

The results of this study shed light on how leaders are viewed from the followers' perspective that differs from most self-assessed leader studies and leader demographics. The study findings indicate that the research study did not represent what previous literature had discovered in regards to Extraversion. Most studies are from self-assessment in terms of leadership and personality perceptions. Surprisingly, Extraversion was not significant in this study. The review of literature for leader demographics indicates that Extraversion is a predictor for Transformational Leadership. Speculation of possible range restriction on Extraversion (lower variance) and Extraversion not being significant is reflected in the outcome of the current study. The findings seem to suggest

Table 1. Summary of findings for Full Range Leadership Model as perceived by the followers'.

\begin{tabular}{rcccc} 
& Number of Participants & Mean & Median & Mode \\
\hline TF L & 241 & 2.90 & 3.0 & 2.95 \\
TA L & 241 & 2.61 & 2.63 & 3.00 \\
PA L & 237 & .95 & .75 & .00 \\
\hline
\end{tabular}

Note: TF L = Transformational Leadership, TA L = Transactional Leadership, and PA L = Passive Avoidant Leadership. 
Table 2. Summary of The Full Range Leadership Model find-

ings.

\begin{tabular}{cccc}
\hline & TF L & TA L & PA L \\
Age & & & \\
Education & & & \\
Ethnicity & & & \\
Gender & M F & M $>$ F & \\
Professional Development & & & \\
Tenure & & & \\
Openness & $\beta=.45$ & $\beta=.38$ & \\
Conscientiousness & & & \\
Extraversion & & & \\
Agreeableness & $\beta=.49$ & & \\
Neuroticism & $\beta=-.25$ & $\beta=-.30$ & $\beta=.20$ \\
\hline
\end{tabular}

that followers' perceptions of elementary principals do differ from self-assessment. Most literature review is self-rated by the leader. In this particular study, the demographics of the followers were used as independent control variables while the followers' perceptions of the elementary principals personality traits and leadership styles were rated. Consistent with literature reviewed on gender, females tend to rate leaders less Transformational than males.

\section{Summary of Findings and Discussion}

Due to significance for each of the hypotheses, all of the null hypotheses were rejected. Contrary to literature review on relationships between personality and leadership styles for self-assessments, the findings follow the pattern of The Full Range Leadership Model for four out of the five personality traits (Openness, Conscientiousness, Agreeableness, and Neuroticism). Extraversion was not a predictor of leadership style as perceived by the followers. In other words, the relationships show a positive correlation starting at the top for Transformational Leadership Style and slowly digressing to a negative relationship for Passive Avoidant Leadership Style, just like The Full Range Leadership Model. The multiple regressions found the strongest predictor for the relationships when all five-personality traits were placed in one group to compete for significance was Neuroticism. See Figure 1 for a visual representation of the Full Range Leadership Model.

The most frequent predictor of leadership style was Neuroticism (Emotional Stability). Neuroticism encompassed the entire range of the Full Range Leadership Model. The more emotionally stable the followers' perceived the elementary principal, the more Transformational and Transactional they rated the principal. The more Neurotic the followers' perceived the elementary principal, the more Passive Avoidant they rated the principal.

The second most frequent predictor of leadership style was Openness. Openness was correlated to both Transformational Leadership and Transactional Leadership. The more effective and active the principals were perceived, the more the followers’ perceived the principals to be Transformational and Transactional.

Agreeableness was only related to Transformational Leadership. Based on the results from the current study, the researcher can only speculate that followers prefer a Transformational and Transactional leader because the followers' seem to like to be rewarded for performance, but also prefer to be left alone. The perceptions seem to represent the profession at the elementary school level. Much contingent reward (Transactional Leadership) occurs between principals and teachers because of the many testing parameters involved needed to comply with district and state guidelines. The findings paint an overall picture of how followers perceive their elementary principals leadership.

\section{Conclusion}

Effective leaders are constantly seeking ways to improve. Elementary principals are in the limelight because 
they tend to be scrutinized for an array of parameters in trying to run successful schools. The perspective of the follower does matter because perception is reality (Sosik, Avolio, \& Jung, 2002). The current study analyzed each of the components of The Full Range Leadership Model. Followers' perceptions of the leaders can prove to be instrumental in helping the leader gauge his/her leadership style based on perceptions of followers'. In conclusion, it is evident that elementary principals are perceived to be more Transformational overall when they are: Open, Agreeable, and Emotionally Stable (score lower on Neuroticism) when rated by followers. Another conclusion is that elementary principals are also perceived to more Transactional when they are Open, score higher on Contingent Reward, and are Emotionally Stable (lower on Neuroticism). Lastly, elementary principals are perceived to be more Passive Avoidant overall when they are Conscientious and Emotionally Unstable (higher on Neuroticism).

Overall, the personality that the leader projects does impact the follower's perception of the leadership style by the elementary principal. As a result, elementary principal's need to understand that follower perceptions can prove to be useful for self-assessment and means for professional development should the leader choose to be effective an efficient. Perception is reality and perception does matter, according to the results of the current study.

\section{Limitations of the Study}

The current sample of convenience study was conducted by surveying participants (elementary teachers and paraprofessionals) from one school district in South Texas that was not necessarily representative of all elementary teachers and paraprofessionals' perceptions. The study focused solely on one district. The sample was not random. The current study was predominantly Hispanic (81\%). Unlike most previous literature review, this study used the perceptions of the followers' rating the leaders' personality traits and leadership styles versus the leaders' self-assessment.

\section{Recommendations-Implications for Future Research}

Much research has been conducted on the relationship between personality and leadership, but the current study analyzed the relationships between The Full Range Leadership Model and The Big Five Personality Traits among elementary school principals from the followers' perspective. Recent studies by Cantu (2012) and Hesbrook (2012) have indicated that leadership styles of principals differ at the elementary, middle, and high school levels. So, the research questions from the present study should be expanded to include middle and high school educational levels. Additionally, future research should include different geographical and demographic contexts, as well as self-assessments by the principals.

\section{References}

Barbuto, J. E., \& Cummins-Brown, L. L. (2007). Full Range Leadership. NebGuide.

Bass, B. M., \& Avolio, B. J. (2004) Multifactor Leadership.Questionnaire-5X Short Form. Redwood City, CA: Mind Garden Bennis, W. (1989). On becoming a Leader. The Leadership Classic. PA: Perseus Books Group.

Chelladurai, P. (1980). Leadership in Sports Organizations. Canadian Journal of Applied Sports Science, 5, $226-231$.

Cantu Jr., R. (2012). Exploring the Relationship between Perceived Principal Leadership Style and Perceived School Climate. Unpublished Doctoral Dissertation, San Antonio, TX: Our Lady of the Lake University.

Connelly, G. (2008). Leading Learning Communities: Standards for What Principals Should Know and Be Able to Do. National Association of Elementary School Principals (NAESP), 2nd Edition.

Daft, R. (2008). The Leadership Experience (4th ed.). Ohio: Thompson South Western.

Davis, S., Darling-Hammond, L., LaPointe, M., \& Meyerson, D. (2005). School Leadership Study: Developing Successful: Principals (Review of Research). Stanford, CA: Stanford University, Stanford Educational Leadership Institute.

Felfe, J., \& Schyns, B. (2010). Follower's Personality and the Perception of Transformational Leadership: Further Evidence for the Similarity Hypothesis. British Journal of Management, 21, 393-410.

Ferrandino, V. (2001). Challenges for $21^{\text {st }}$-Century Elementary. School Principals. Phi Delta Kappan, 82, 440-442.

Gardner, J. W. (1990). On Leadership. New York: The Free Press.

George, B. (2003). Authentic Leadership: Rediscovering the Secrets to Creating Lasting Value. San Francisco, CA: Jossey-Bass. 
Goldberg, L. R. (1999). A Broad-Bandwidth, Public Domain Personality Inventory Measuring the Lower-Level Facets of Several Five-Factor Models. In I. Mervielde, I. Deary, F. De Fruyt, \& F. Ostendorf (Eds.), Personality Psychology in Europe, Vol. 7 (pp. 7-28). Tilburg, The Netherlands: Tilburg University Press.

Hesbrook, H. (2012). A Study of Leadership Behavior Preferences, Individualism/Collectivism Preferences, and Academic Performance. Unpublished Doctoral Dissertation, San Antonio, TX: Our Lady of the Lake University.

Judge, T. A., Bono, J. E., Llies, R., \& Gerhardt, M. W. (2002). Personality and Leadership: A Qualitative and Quantitative review. Journal of Applied Psychology, 87, 765-780. http://dx.doi.org/10.1037/0021-9010.87.4.765

Karaköse, T. (2008). The Perceptions of Primary School Teachers on Principal Cultural Leadership Behaviors. Educational Sciences: Theory and Practice, 8, 569-579.

Kenny, D. A., \& Zaccaro, S. J. (1983). An Estimate of Variance due to Traits in a Leader. Journal of Applied Psychology. http://dx.doi.org/10.1037/0021-9010.68.4.678

Lewis, J. D., Cruzeiro, P. A., \& Hall, C. A. (2007). Impact of Two Elementary School Principals’ Leadership on Gifted Education in Their Buildings. Gifted Child Today, 30, 56-62.

Lord, R. G., De Vader, C. L., \& Alliger, G. M. (1986). A Meta-Analysis of the Relation between Personality Traits and Leadership Perceptions: Procedures. Journal of Applied Psychology, 71, 402-410. http://dx.doi.org/10.1037/0021-9010.71.3.402

Lord, R. G., \& Maher, K. J. (1991). Leadership and Information Procession: Linking Perceptions and Performance. New York: Unwin Hyman Inc.

Moffet, C. (1979). The Elementary Principal: A First Year Perspective. Theory into Practice, 18, 8-12. http://dx.doi.org/10.1080/00405847909542802

Moore, B. (2009). Emotional Intelligence for School Administrators: A Priority for School Reform? American Secondary Education, 37, 20-28.

Moss, S. A., \& Ngu, S. (2006). The Relationship between Personality and Leadership Preferences. Current Research in Social Psychology, 11, 70-91.

Schyns, B., \& Sanders, K. (2007). In the Eyes of the Beholder: Personality and the Perception of Leadership. Journal of Applied Social Psychology, 37, 2345-2363. http://dx.doi.org/10.1111/j.1559-1816.2007.00261.x

Sosik, J. J., Avolio, B. J., \& Jung, D. I. (2002). Beneath the Mask: Examining the Relationship of Self-Presentation Attributes and Impression Management to Charismatic Leadership. The Leadership Quarterly, 13, 217-242. http://dx.doi.org/10.1016/S1048-9843(02)00102-9 